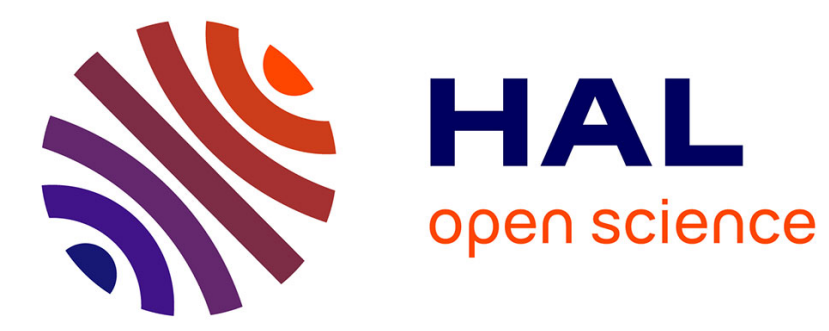

\title{
Unexpected REM Sleep Excess Associated with a Pontine Lesion in Multiple Sclerosis
}

Sinead Zeidan, Stefania Redolfi, Caroline Papeix, Benedetta Bodini, Céline Louapre, Isabelle Arnulf, Élisabeth Maillart

\section{- To cite this version:}

Sinead Zeidan, Stefania Redolfi, Caroline Papeix, Benedetta Bodini, Céline Louapre, et al.. Unexpected REM Sleep Excess Associated with a Pontine Lesion in Multiple Sclerosis. Journal of Clinical Sleep Medicine, In press, 10.5664/jcsm.9114 . hal-03184229

\section{HAL Id: hal-03184229 \\ https://hal.sorbonne-universite.fr/hal-03184229}

Submitted on 29 Mar 2021

HAL is a multi-disciplinary open access archive for the deposit and dissemination of scientific research documents, whether they are published or not. The documents may come from teaching and research institutions in France or abroad, or from public or private research centers.
L'archive ouverte pluridisciplinaire HAL, est destinée au dépôt et à la diffusion de documents scientifiques de niveau recherche, publiés ou non, émanant des établissements d'enseignement et de recherche français ou étrangers, des laboratoires publics ou privés. 


\section{Unexpected REM Sleep Excess Associated with a Pontine Lesion in Multiple Sclerosis}

Sinéad ZEIDAN, MD1, Stefania REDOLFI, MD, PhD2,3, Caroline PAPEIX, MD, PhD1', Benedetta BODINI, MD4,5, Céline LOUAPRE, MD, PhD ${ }^{1,4}$, Isabelle ARNULF, MD, PhD²,4, Elisabeth MAILLART, MD, PhD1

${ }^{1} A P-H P$, Pitié-Salpêtrière Hospital, Department of Neurology, Paris, France

${ }^{2} A P-H P$, Pitié-Salpêtrière Hospital, Centre de Référence narcolepsie et hypersomnies rares, Service de Pathologies du Sommeil, Paris, France

3Sorbonne Université, INSERM, UMRS1158 Neurophysiologie Respiratoire Expérimentale et Clinique, Paris France.

4Institut du Cerveau et de la Moelle épinière, ICM, CIC Neuroscience, Paris, France ${ }^{5}$ AP-HP, Saint Antoine Hospital, Department of Neurology, Paris, France

Institution where the work was performed: Hôpital Pitié-Salpêtrière, APHP-Sorbonne, Paris

Correspondence to: Isabelle Arnulf, Service des Pathologies du Sommeil, Hôpital Pitié-Salpêtrière, 47-83 Boulevard de l'Hôpital, 75013 Paris, France ; Email : isabelle.arnulf@aphp.fr ; Phone: 33142167702 ; Fax: 33142167700

\section{Statements}

- All authors have seen and approved the manuscript

- None of the authors has any conflict of interest relative to this case report

- Number of tables: 0; Number of figures: 1; colored figure: 1

- Words count: Abstract: 121; Manuscript text: 915; Legend: 65; Number of references: 12

Keywords: Multiple sclerosis, REM sleep, pontine lesion

Submitted to: JCSM, version \#2 ; type of manuscript: Case Reports. 
Disclosure/conflict of interest statement: The authors declare that they have no conflict of interest.

Funding statement: The patient participated in a larger trial on respiratory disease in multiple sclerosis (RespiMus study, describing respiratory disorders among patients with severe multiple sclerosis, NCT03339817), funded by grants from Novartis Pharma and Roche Pharma. 


\section{Abstract}

Sleep disorders are prevalent in patients with multiple sclerosis. In contrast, a frank increase of REM sleep time is a rare phenomenon, mostly described in the context of REM sleep rebound (after sleep deprivation, abrupt withdrawal of antidepressants or neuroleptics, and during the first night of ventilation for severe sleep apnea), but not in link with specific brain lesions. We incidentally found an isolated, marked increase in REM sleep time (200 min, 40\% of total sleep time, normative values: $18.2-20.3 \%$ ) and in rapid eye movements density during REM sleep in a patient with a secondary progressive multiple sclerosis, associated with an anterior pontine demyelinating lesion on MRI. This result suggests that a network blocking REM sleep in the pons has been damaged. 


\section{INTRODUCTION}

An increased prevalence of sleep disorders is reported in patients with multiple sclerosis, including insomnia, restless legs syndrome, periodic limb movement disorder, sleep-related breathing disorders, narcolepsy, hypersomnia and rapid eye movement (REM) sleep behavior disorder. ${ }^{1,2}$ A frank increase of REM sleep time is a rare phenomenon, which has been mostly described in the context of REM sleep rebound after REM sleep deprivation, ${ }^{3}$ including abrupt withdrawal of antidepressants or neuroleptics (which reduce REM sleep) and during the first night of treatment of severe sleep apnea. ${ }^{4}$ However, an increase of REM sleep time has not been reported in relationship with specific brain lesions. We report a case of incidental increased REM sleep time in a patient with secondary progressive multiple sclerosis.

\section{CASE REPORT}

A 47 year-old woman followed for a secondary progressive multiple sclerosis underwent a video-polysomnography in the setting of a study describing respiratory disorders in patients with severe multiple sclerosis. She had been diagnosed with multiple sclerosis when she was 28 years old, and developed a secondary progressive phenotype 7 years later. She had no other medical history. Expanded Disability Status Scale score was 7/10, as she was able to walk only 5 meters with 2 aids. The ongoing treatments included fampridine (prolonged-release, $10 \mathrm{mg}$ twice daily), baclofene (10 $\mathrm{mg}$ daily), fluoxetine (20 $\mathrm{mg}$ daily), and occasionally bromazepam $1.5 \mathrm{mg}$ at bedtime. She reported a mildly increased daytime sleepiness (score at the Epworth sleepiness scale: 12/24), and on average $8 \mathrm{~h}$ of sleep per night, which was felt as restorative. She had no snoring, nycturia, restless legs, abnormal behavior during sleep, sleep paralysis, hypnagogic hallucinations, cataplexy, or lucid dreams). Dream recall frequency was 3.5 dreams/month. She had no current symptom of depression. Importantly, she had not recently discontinued or reduced her antidepressant treatment with fluoxetine, and there was no recent sleep deprivation. 
The video-polysomnography showed mildly increased total sleep time (TST, $494.5 \mathrm{~min}$, normative values: $371.4-401.9 \mathrm{~min})^{5}$ and sleep efficiency $(94.2 \%$, normative values: $83.7-87.1 \%$, and mildly decreased sleep onset $(8.5 \mathrm{~min})$, and REM sleep latencies $(75.5 \mathrm{~min})$. The duration of REM sleep was dramatically increased, representing 200 min and 40.4\% of TST (normative values: 18.2-20.3\%) (Figure 1A), to the expense of N2 sleep which represented 32.8\% of TST (normative values: $50.6-53.8 \%)$, whereas N3 sleep was mildly increased (26.8\% of TST, normative values: 18.5 22.2\%). In REM sleep, there was a normal atonia (REM sleep without atonia: $1.3 \%$ of REM duration, normal $<18 \%),{ }^{6}$ but the density of rapid eye movements was increased (67.5\% of REM sleep duration, when $20 \%$ are expected on average). ${ }^{7}$ The arousal plus awakening index was normal $(12.9 / \mathrm{h})$. There was no sleep-related breathing disorder (apnea-hypopnea index was 1.2/h, absence of hypoventilation on transcutaneous $\mathrm{CO}_{2}$ monitoring). The periodic leg movement index was $15.3 / \mathrm{h}$, and the periodic leg movement arousal index was $0.5 / \mathrm{h}$. Brain magnetic resonance imaging showed disseminated supra-tentorial and cerebellar demyelinating lesions, as well as a lesion in the ventral part of the pons, as shown in Figure 1B.

\section{DISCUSSION}

There was a major increase of REM sleep time and percentage in a patient with progressive multiple sclerosis, associated with an anterior pontine demyelinating lesion. REM sleep structure contained an excess of eye movements but a normal muscle atonia. This sleep pattern was not otherwise explained by a REM rebound after withdrawal of antidepressants or sleep deprivation, nor by a depression, which are the usual causes of increased REM sleep. ${ }^{8}$ On the contrary, the patient was routinely treated with drugs supposed to reduce REM sleep (including fluoxetine, baclofene and bromazepam).

Dysregulation of REM sleep associated with demyelinating lesions in multiple sclerosis has been reported in rare cases, including pontine tegmentum lesions causing REM sleep behavior disorder, or bilateral hypothalamic lesions causing narcolepsy. ${ }^{9}$ However, increased REM sleep time 
has not been linked to demyelinating lesions, to the best of our knowledge. Polysomnographic studies have shown a normal REM sleep duration in patients with multiple sclerosis. ${ }^{2,10}$

In animal models, REM sleep is generated by a group of neurons located in the dorsal pontine tegmentum, which include in the rat the caudal laterodorsal tegmental nucleus, sublaterodorsal nucleus and precoeruleus region, and in the cat the peri-locus coeruleus alpha (equivalent to the locus subcoeruleus in human brain). ${ }^{11}$ REM-on cells are blocked by monoaminergic pathways (including serotonergic fibers emerging from the raphe nucleus, and norepinephrine fibers from the locus coeruleus), as well as by descending fibers from the hypothalamus (hypocretinergic and histaminergic nuclei) and gamma-aminobutyric acidergic neurons from the ventrolateral periaqueductal gray matter and lateral pontine tegmentum. ${ }^{12}$ A damage in any of these tracts may cause excessive REM sleep time and possibly excessive REMs. Interestingly, this increase is selective of REM sleep, as NREM sleep time is normal, and muscle atonia is maintained during REM sleep (indicating that the locus subcoeruleus is intact). However, we cannot be certain that the pontine lesion causes the REM sleep excess, in absence of a time sequence showing that REM sleep time returns to normal values when the lesion disappears.

The clinical consequences of increased REM sleep time are not known. A mild increase of REM sleep (but not to the point of reaching $40 \%$ of total sleep time) is a trait marker of depression, although it remains unclear whether it is causative or only a common marker of low serotonin levels in the brain. ${ }^{8}$ Nevertheless, focal lesions of the brainstem associated with specific sleep disturbances are rare and need to be reported, especially in multiple sclerosis, as they support the role of the pons in REM sleep control in humans.

\section{REFERENCES}

1. Veauthier C. Sleep disorders in multiple sclerosis. Review. Curr Neurol Neurosci Rep 2015;15:21.

2. Neau JP, Paquereau J, Auche V, et al. Sleep disorders and multiple sclerosis: a clinical and polysomnography study. Eur Neurol 2012;68:8-15. 
3. Hornung OP, Regen F, Schredl M, Heuser I, Danker-Hopfe H. Manipulating REM sleep in older adults by selective REM sleep deprivation and physiological as well as pharmacological REM sleep augmentation methods. Exp Neurol 2006;197:486-94.

4. Aldrich M, Eiser A, Lee M, Shipley JE. Effects of continuous positive airway pressure on phasic events of REM sleep in patients with obstructive sleep apnea. Sleep 1989;12:413-9.

5. Boulos MI, Jairam T, Kendzerska T, Im J, Mekhael A, Murray BJ. Normal polysomnography parameters in healthy adults: a systematic review and meta-analysis. Lancet Respir Med 2019;7:53343.

6. Frauscher B, Gabelia D, Mitterling T, et al. Motor events during healthy sleep: a quantitative polysomnographic study. Sleep 2014;37:763-73, 73A-73B.

7. Leclair-Visonneau L, Oudiette D, Gaymard B, Leu-Semenescu S, Arnulf I. Do the eyes scan dream images during rapid eye movement sleep? Evidence from the rapid eye movement sleep behaviour disorder model. Brain 2010;133:1737-46.

8. Riemann D, Krone LB, Wulff K, Nissen C. Sleep, insomnia, and depression. Neuropsychopharmacology 2020;45:74-89.

9. Foschi M, Rizzo G, Liguori R, et al. Sleep-related disorders and their relationship with MRI findings in multiple sclerosis. Sleep medicine 2019;56:90-7.

10. Chen JH, Liu XQ, Sun HY, Huang Y. Sleep disorders in multiple sclerosis in China: clinical, polysomnography study, and review of the literature. Journal of clinical neurophysiology : official publication of the American Electroencephalographic Society 2014;31:375-81.

11. Peever J, Fuller PM. The Biology of REM Sleep. Curr Biol 2017;27:R1237-R48.

12. Sapin E, Lapray D, Berod A, et al. Localization of the brainstem GABAergic neurons controlling paradoxical (REM) sleep. PLoS One 2009;4:e4272. 


\section{Abbreviation list:}

REM: rapid eye movement

TST: total sleep time

Figure legend:

Figure 1: Increased REM sleep time associated with a pontine lesion.

A: Hypnogram of the patient, showing excessive REM sleep time, representing 200 minutes and $40.4 \%$ of total sleep time (normal: 18.2-20.3\%). W: wake; R: REM stage; 1, 2 and 3: Non-REM sleep, stage N1, N2 and N3.

B: MRI of the patient (sequence T2), axial and sagittal sections, showing the pontine lesion (red arrow).

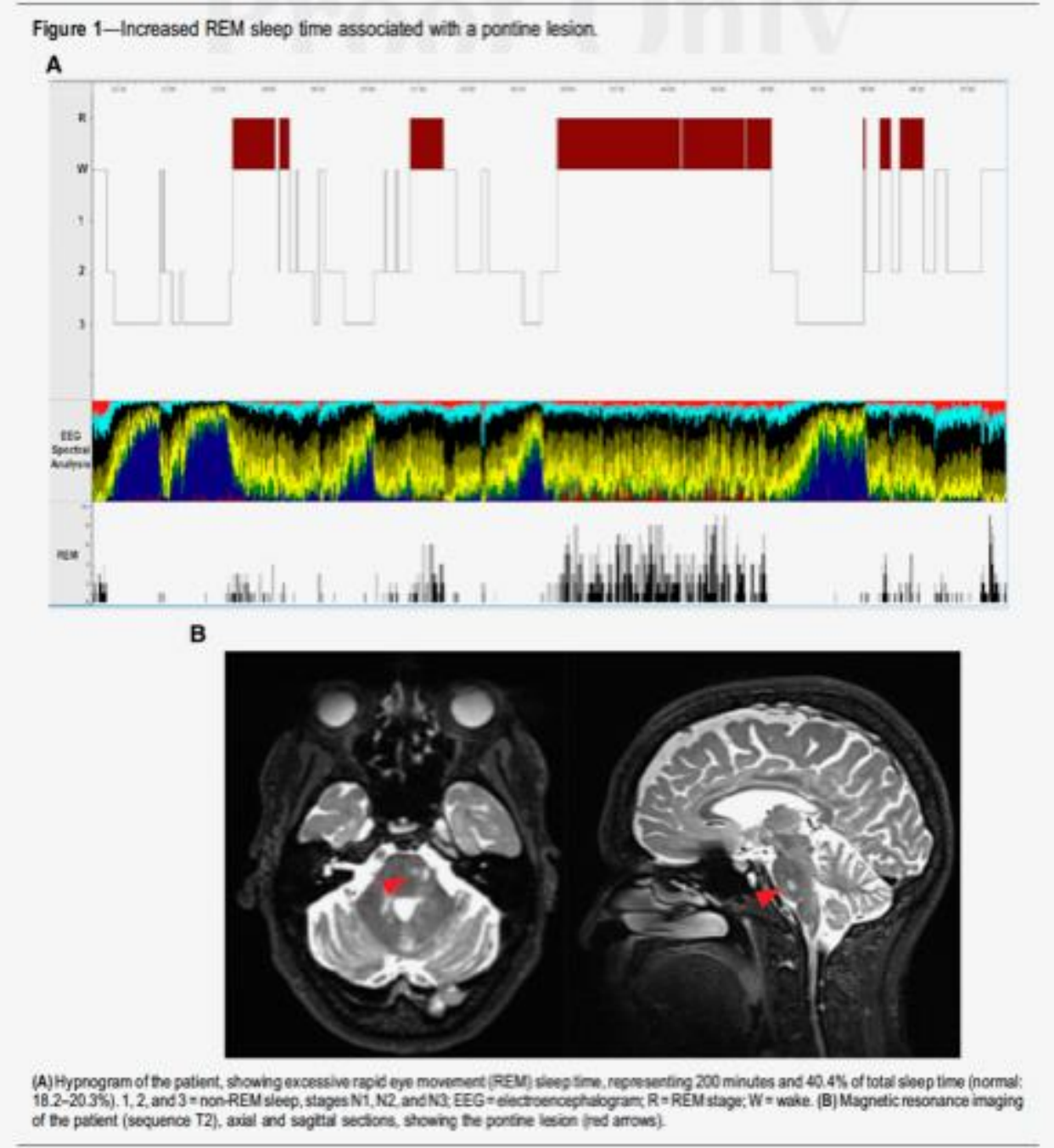

